\title{
Selective Amygdalohippocampectomy: Indications and Follow-up
}

\author{
Heinz Gregor Wieser
}

\begin{abstract}
Selective amygdalohippocampectomy (AHE) offers a real chance of cure only in patients with welldefined, precisely localized "epileptogenic area", i.e. seizure focus. Therefore, a priori only a small proportion of all patients with epilepsy can meet the criteria for selective surgical interventions. From the evidence in patients meeting the criteria for AHE, we conclude that this technique is to be preferred to the "standard" anterior temporal lobectomy and represents a more selective but still effective surgical treatment of epilepsy.

RÉSUMÉ: L'amygdalo-hippocampectomie sélective: Indications et suivi. L'amygdalo-hippocampectomie sélective offre de réelles chances de guérison de l'épilepsie seulement chez les patients avec une "zone épileptique" bien définie, bien localisée et de dimension restreinte, c'est-à-dire un foyer épileptique. Donc, à priori, seulement une faible proportion des patients épileptiques pourront satisfaire auz critères les rendant éligibles à une chirurgie sélective. En se basant sur les résultats des séries que nous avons présentées, nous sommes en mesure d'affirmer qu'une amydalojhippocampectomie sélective, chez des patients rencontrant les critères d'éligibilité, est préférable à une lobectomie temporale antérieure. En conclusion, nous espérons que l'amygdalo-hippocampectomie sélective, telle que décrite plus haut, constituera un pas vers une approche chirurgicale plus ciblée, et tout aussi efficace, de l'épilepsie.
\end{abstract}

Can. J. Neurol. Sci. 1991; 18: 617-627

Since the pioneering work of the Montreal school ${ }^{1-6}$ the surgical treatment of epilepsy has continued to achieve worldwide acceptance as an alternative treatment for selected patients with medically refractory seizures. Patients with temporal lobe (TL) seizures still constitute the most important group in the surgical series. The advent of modern diagnostic methods has aided the recognition of certain subtypes of complex partial seizures. ${ }^{7-8}$ Improved diagnosis and better understanding of the importance of the mesial temporal region in the pathogenesis of TL seizures has resulted in more selective operations. New diagnostic methods, such as the foramen ovale electrode ${ }^{9}$ and other special extracranial electrodes technologies have led to better presurgical assessment. ${ }^{10}$

The first selective temporal lobe resections for treatment of mesiobasal limbic epilepsy7, 11-13 were performed at our University Hospital by Yasargil in 1975. Operative anatomy, surgical techniques, criteria for operation, investigative techniques and results of the "selective amygdalohippocampectomy" (AHE) have been previously reported. ${ }^{11,14-18}$

We have recently completed three studies on our patients who underwent AHE: 1) a detailed volumetric examination of surgical resection on pre- and postoperative MR imaging ( $\mathrm{N}=$ $\left.30),{ }^{19} 2\right)$ a year by year post-surgical follow-up $(\mathrm{N}=20),{ }^{20}$ and 3 ) a detailed analysis of 320 seizures recorded in 77 patients ${ }^{21}$ with foramen ovale electrodes. The aim of this paper is to correlate the above three studies and to summarize indications and results of AHE.

\section{Indications for Selective Amygdalohippocampectomy}

The microsurgical AHE procedure is the result of both a precise identification of the seizure-initiating structures (and preferential pathways of seizure spread) and the refinements of neurosurgical techniques. ${ }^{22-23}$ Our analysis of seizures recorded by stereo-electroencephalography (SEEG) ${ }^{24}$ indicated that the "classical" anterior TL resection may be a needless and aggressive operation for patients with an unequivocally demonstrated seizure focus in the mesiobasal limbic area. At our institution, the majority of patients, evaluated for medically refractory complex partial seizures (cps), showed a strictly focal unilateral mesiobasal seizure focus involving the hippocampal formation and the amygdala. In our series, approximately $65 \%$ of the patients showed high-frequency low-amplitude discharges simultaneously in the hippocampus and the amygdala at the onset of each seizure (Figure 1). Seizure discharges recorded only in the hippocampal formation and initially not affecting the ipsilateral amygdala constituted another $25 \%$ (Figure 2). About $7 \%$ of mesiobasal limbic seizures started in the amygdala and propagated to the hippocampus within 3 to $5 \mathrm{sec}$. Only $3 \%$ of the patients showed tonic discharges exclusively confined to the amygdala without hippocampal spreading at the onset of seizure.

Specific requirements for "causal" AHE are the following: 1) the seizure focus must be in the mesiobasal limbic structures ipsilateral to the side chosen for resection, and 2) the contralateral mesiobasal TL must be functional. 

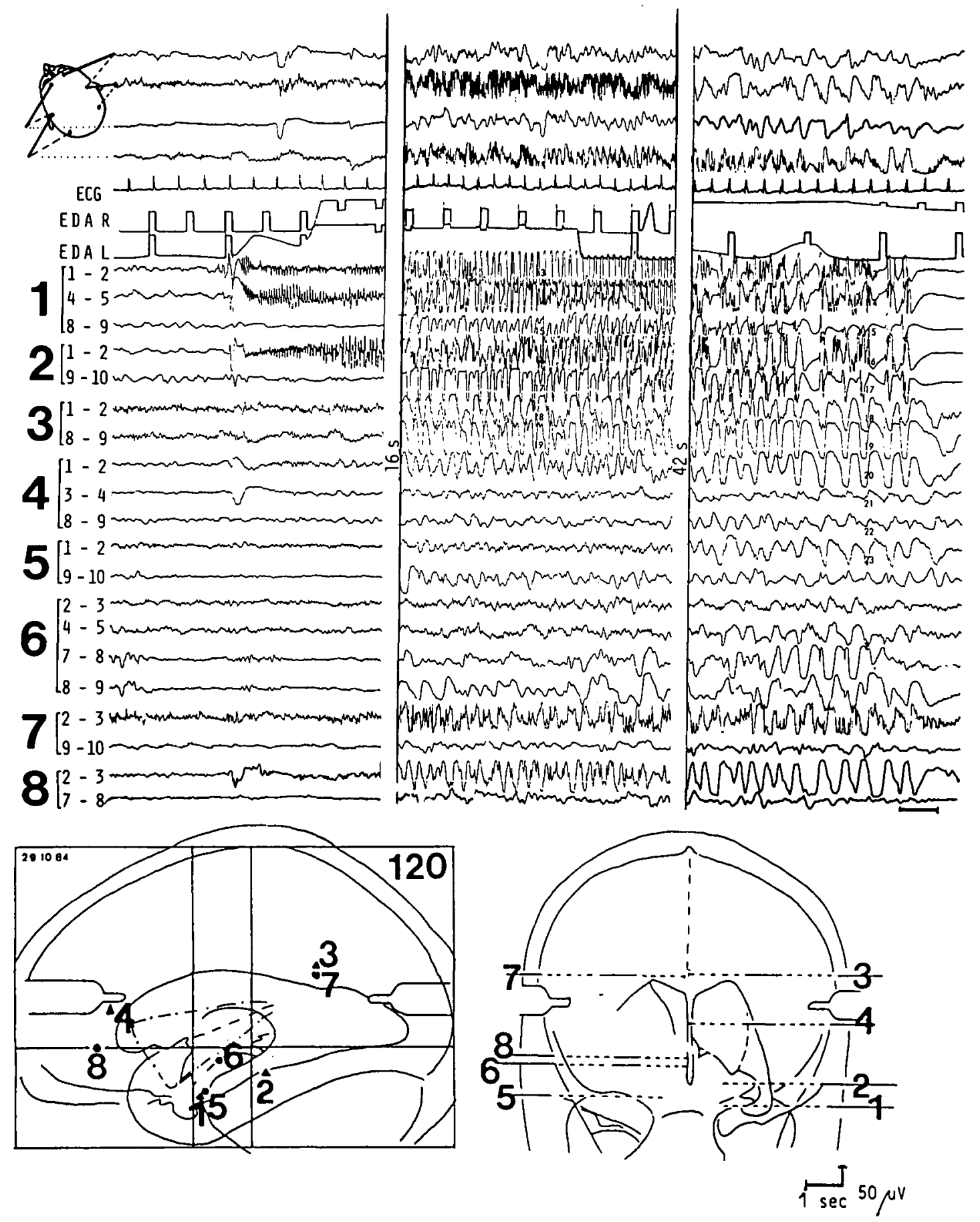

Figure I - Combined scalp-and depth EEG recordings at onset, peak, and end of a spontaneously occurring complex partial seizure. The initial epileptic discharge is simultaneously recorded in the left amygdala (1/1-2 and $1 / 4-5)$ and left hippocampus (2/1-2). Note the increased electrodermal activity (EDA L) recorded from a left hand finger at the onset of seizure, the tachycardia (ECG) at the peak of seizure, and the postictal depression in the depth-EEG left temporal derivations.

The seizure was characterized by an epigastric aura, staring, progressive impairment of consciousness, unresponsiveness and oral-alimentary automatisms (second section).

The position of the 10-polar hollow-core depth electrodes (bold numbers) is indicated in the brain maps. The small numbers refer to the contacts of each depth electrode. The length of the contacts and the intercontact spacing is $2 \mathrm{~mm}$ with the exception of intercontact distance 5-6. Contact I is the deepest and contact 10 is the most superficial in each electrode. The external diameter of the stainless steel electrodes is $0.9 \mathrm{~mm}$. 


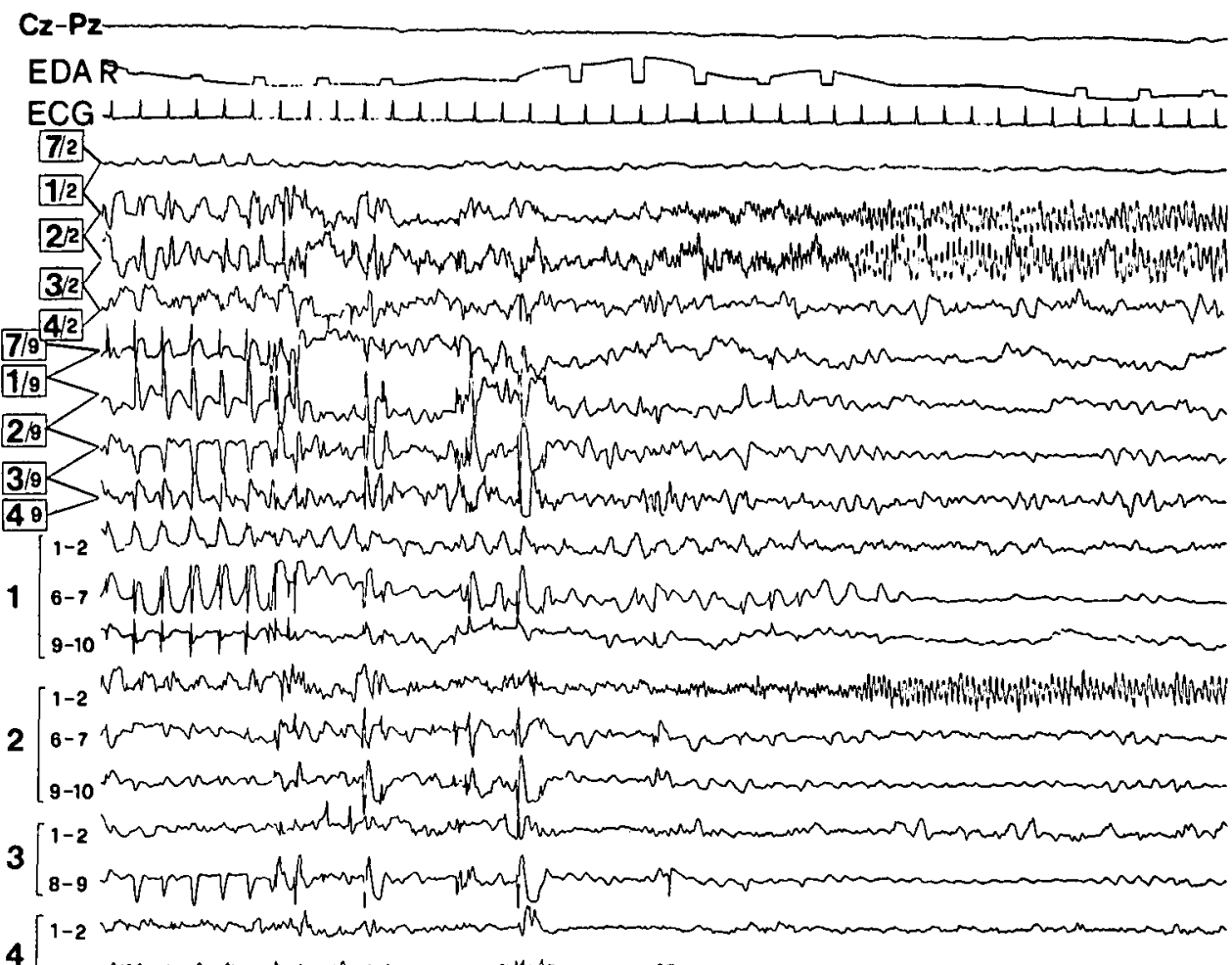

4

5

[1-2

B-9

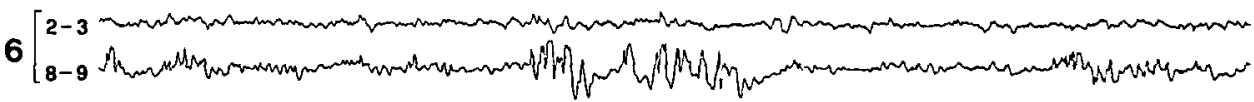

$7[$ 8-9 ح-1-2

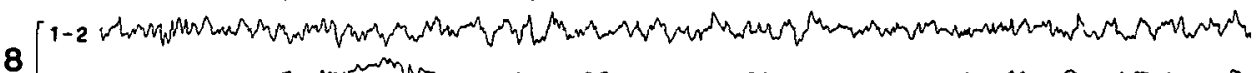

8

$9\left[\begin{array}{lll}2-3 \\ 8-9\end{array}\right.$

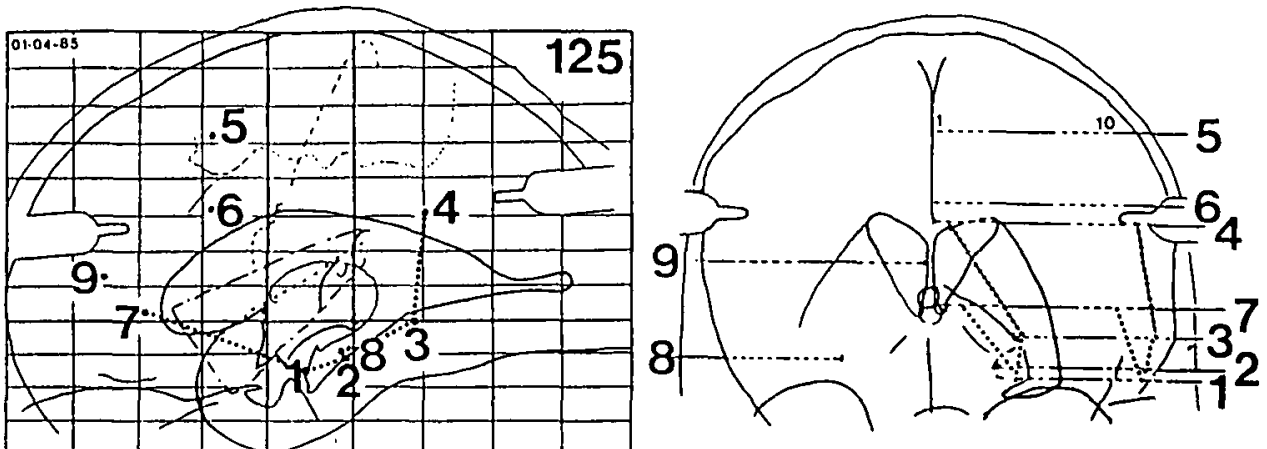

Figure 2 - Example of depth EEG recording at the onset of a seizure, characterized by an aura of detachment. Note the special montage, which consists of uninterrupted bipolar long distance derivations in the parasagittal plane (... in the brain map). connecting the deep (channels 4-7) and the superficial contacts (channels 8-11) of electrodes 7, 1, 2, 3, 4 and of interrupted short-distance derivations along electrodes l-9 (channels 12-31). Note that the pre-ictal epileptiform activity consists of fairly regular $2 /$ sec spike-slow-wave complexes with a clear predominance in the anterior lateral temporal neocortex (left), whereas the low-voltage high-frequency ictal discharge (right) is clearly localized to the anterior hippocampus (electrode 2, contact 2). In addition to the depth EEG, one scalp derivation (Cz-Pz), the electrocardiogram (ECG) and the electrodermal activity recorded from the right fingers (EDA $R$ ) are shown. Calibration refers to surface and depth EEG only. (From Wieser, 1987b). 
In reality, the first requirement is somewhat relative. Since 1979, we considered selective AHE to be indicated also in patients with either a seizure focus greater than the eventually resected amygdala and hippocampus or with a seizure focus outside the amygdalohippocampal complex, but with the mesiobasal limbic structures acting as a "secondary pacemaker". These two events constitute the rationale for the so-called "palliative" AHE (as opposed to "causal" AHE with a seizure focus strictly localized within the resected structures).

To better assess the preoperative risks of selective AHE on higher cognitive functions, such as learning and memory, we developed three selective TL-Amytal procedures. ${ }^{25-26}$ During preoperative neuropsychological evaluation we are now using one of the following techniques for the Amytal test: 1) temporal balloon-occlusion distal to the anterior choroidal artery (a.ch.a.) with subsequent Amytal injection into the a.ch.a., the communicans posterior and the ophthalmic artery; 2) selective catheterization of the a.ch.a.; and c) the selective characterization of the P2 segment of the posterior cerebral artery. These modifications of the "Wada-Test"6, 27-28 have been proven to be better predictors of neuropsychological outcome for selective AHE patients. ${ }^{29}$ Further studies investigating individual variations of the vascular territories of injected vessels are necessary.

\section{Rationale for Amygdalohippocampectomy}

The aim of our standard AHE technique is the complete removal of the amygdala, the anterior hippocampus, and part of the parahippocampal gyrus (Figure 3). It is important to note that the resection of the subiculum which can act as a "hyperexcitable fringe" and therefore as an amplifier ${ }^{7,}, 30$ constitutes an important aspect of this operation. Furthermore, the surgical trans-Sylvian approach to the amygdala (the first target of the neurosurgeon) is through the medial aspect of the first temporal gyrus. This initial operative step interrupts the anterior commissure and at the same time the uncinate fasciculus. Thus, the resection of the epileptic focus is combined with the interruption of the main propagation pathways operative in most mesiobasal limbic seizures ${ }^{31}$ (see also Figure 4).

Recently, we completed a study in which we measured the total volume of surgically resected brain in AHE and the percentage of the following structures: amygdala, hippocampus, and parahippocampal gyrus. The percentage of resection of pes hippocampi, dentage gyrus, uncus, and subiculum (as defined by Duvernoy) ${ }^{32}$ was also measured. The study was performed in 30 patients who had special pre- and postoperative MR imaging and a postoperative clinical follow-up of at least one year. Postoperative seizure control was correlated with the total resected volume and with the proportions of resected volume of each of the above mentioned limbic subcompartments (as judged independently by two investigators). The following results were obtained. 19

The mean volume of the removed tissue was $7.2 \mathrm{ml}$ (range 2.1 to 17.7). The percentage scores of the limbic subcompartments were: amygdala $92 \%$, hippocampus $46 \%$, parahippocampal gyrus $32 \%$, pes hippocampi $92 \%$, dentate gyrus $45 \%$, uncus $92 \%$, and subiculum $40 \%$. Although a small resection did not exclude a good outcome, there was a trend showing that a better outcome was associated with a larger resection. Of note is that the incomplete resection of the parahippocampal gyrus, and in particular of the subiculum, resulted in a less satisfactory out- come (Figure 5). These data show that the rationale for AHE aims at both, elimination of the seizure generating structures and interruption of pathways important for the maintenance and spread of seizure discharges.

\section{Results of Amygdalohippocampectomy}

Two hundred sixty-six patients with medically refractory mesiobasal TL epilepsy underwent selective TL surgery in the University Hospital of Zürich since 1975. Excluding patients who underwent selective TL resections outside the amygdala and hippocampus, 215 patients underwent selective AHE. These 215 patients have been classified according to the neuropathological findings of the resected specimen. All specimens were examined by routine and immunohistochemical staining procedures including antibodies to glial fibrillary acidic protein (GFAP) and synaptophysin. Brain tumors were found in 110 patients $(48 \%)$. The tumors included fibrillary astrocytoma (22\%), mixed oligo-astrocytoma (14\%), ganglioglioma (13\%), pilocytic astrocytoma (13\%), oligodendroglioma (11\%), glioblastoma (10\%), anaplastic astrocytoma (8\%), and others (9\%). Vascular malformations were diagnosed in $12 \%$, and neuronal, glial and neuro-glial hamartomas in $7 \%$ of the total number of cases. In 37 patients (17\%) reactive gliosis in the hippocampus was present and in 2 patients (1\%) findings consistent with sequelae of an encephalitis were found. In 34 patients $(16 \%)$ no structural alterations were detected.

The male to female ratio was 120 vs 95 . In 114 patients the operation was on the right and in 101 patients on the left side. Mean age at the onset of the seizure disorder was 18.8 years (SD 15.3), and the mean age at operation was 29.7 years (SD 13.7). The calculated mean duration of the seizure disorder prior to operation was 11.0 (SD 10.2) years. Patients with benign tumors were operated at younger age (mean 29.2; SD 29.6 years) than those with malignant tumors (mean 37.3; SD 16.7 years).

Patients with no microscopical pathology were operated earlier (mean 28.0; SD 8.8 years) than those with slight gliosis (mean 30.1; SD 10.6 years). Patients with moderate gliosis (mean 32.2; SD 9.6 years) were operated earlier than those with severe gliosis (mean 34.1; SD 7.3 years).

The shortest duration of the seizure disorder prior to the operation was found in patients with malignant tumors (mean 3.7; SD 5.8 years), followed by patients with semibenign tumors (mean 6.0; SD 7.2 years) and patients with benign tumors (mean $9.0 ;$ SD 7.1 years).

The mean duration of epilepsy prior to surgery was 18.5 (SD 8.1) years in patients with slight gliosis, 21.9 years (SD 9.1) in cases with moderate gliosis, and 28.8 years (SD 4.5) in patients with severe gliosis.

The epileptological outcome was classified according to Engel's recommendations ${ }^{33}$ into the following categories: I, seizure free; II, rare seizures (not more than 1-2 per year); III, worthwhile improvement ( $\geq 90 \%$ reduction); and IV, no worthwhile improvement. A postoperative follow-up of at least 12 months was required prior to classification in one of the above categories. One hundred seventy-seven patients out of the 215 who underwent AHE met the above criterion for classification. The most recent epileptological outcome together with the follow-up period is reported in Table 1. The year-by-year outcome classification shows that the percentage of patients in each out- 

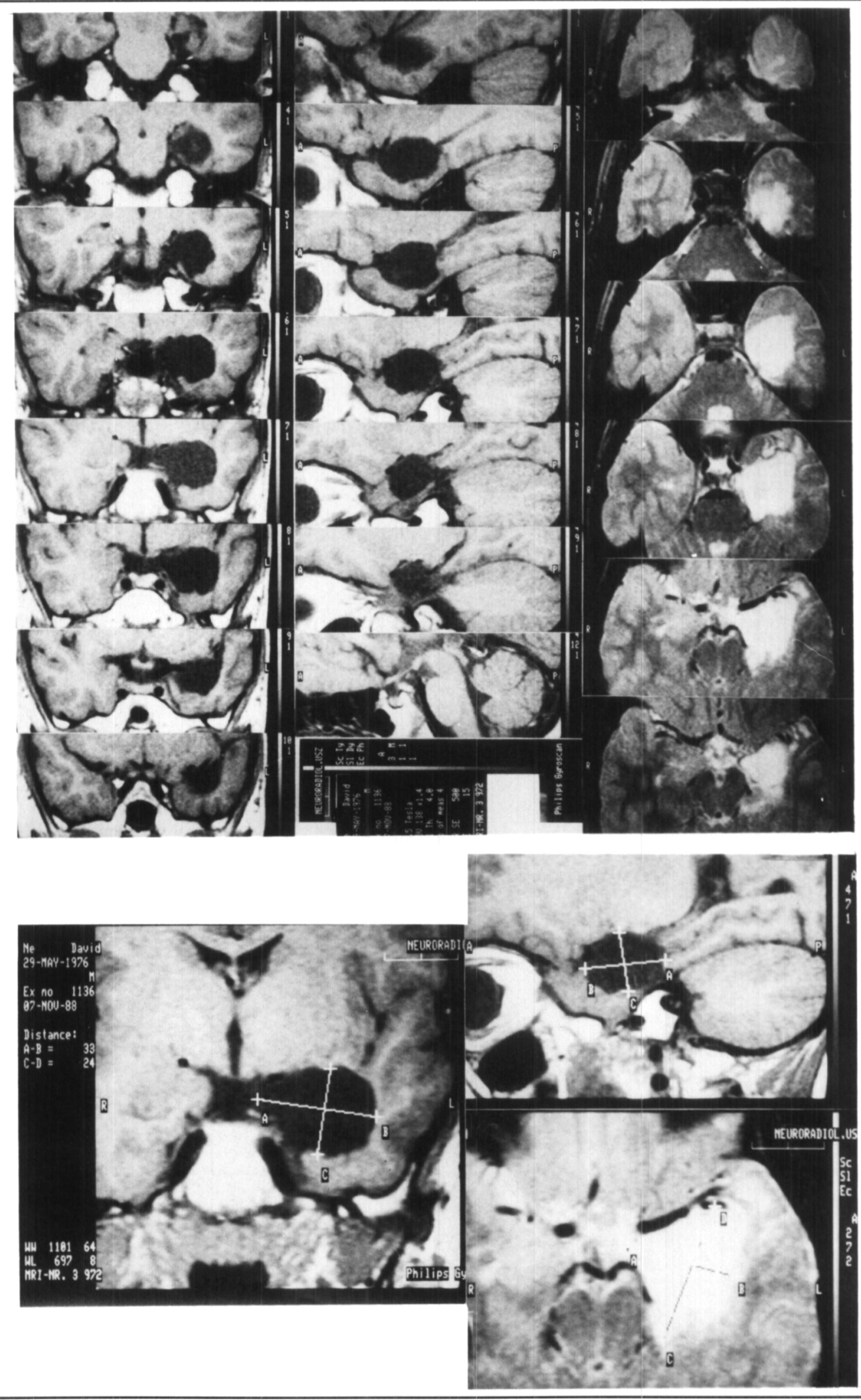

Figure 3-Serial postoperative MR-images in all three planes showing the extent of a left selective amygdalohippocampectomy. Coronal and sagittal images are $T_{1}$-weighted, transversal images are $T_{2}-$ weighted. 1.5 Tesla system (Philips). Repetition time $500 \mathrm{msec}$, echo time $15 \mathrm{msec},\left(T_{2}:\right.$ double echo 50/100, TR 2000); $256 \times 256$ matrix, field of view $200 \mathrm{~mm}$; slice thickness $4 \mathrm{~mm}$. 

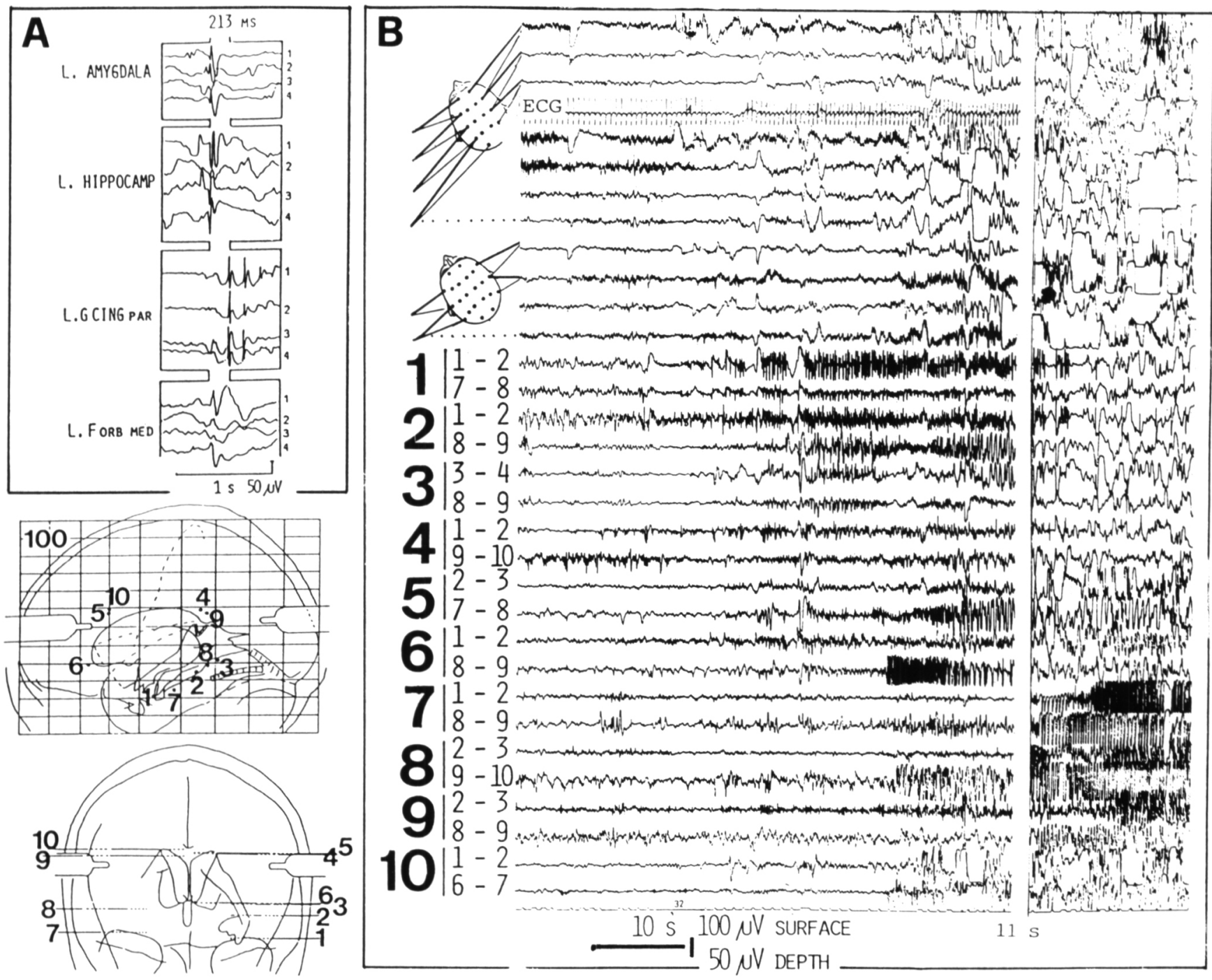

\section{STIM: L HIPPOC}
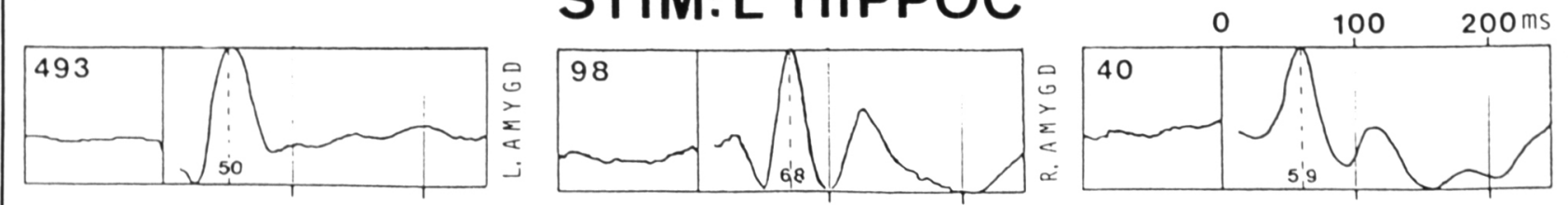

Figure 4 - Interictal spike $(A)$ and ictal discharge propagation $(B)$ to ipsilateral frontal regions, most probably mediated through the uncinate fasciculus. Ipsilateral (C left) and contralateral ( $C$ middle) amygdalar and contralateral hippocampal response (C right) following repetitive left hippocampal single pulse stimulation $(10 \mathrm{~V}, 0.7 \mathrm{~ms}, 1 \mathrm{~Hz}$; averaged response, $\mathrm{N}=102)$ are also shown.

Parts $A$ and $B$ are from the same patient, whose brain map with the electrode position is shown. In A, four spontaneously occurring spikes are depicted (numbered by small numbers 1-4, on the right margin) and arranged vertically in order to better visualize the stereotype propagation. The primary epileptogenic area has been localized in the left amygdala and hippocampus, based on the spontaneous seizures (see B). These find. ings were confirmed by complete seizure control following selective left amygdalohippocampectomy. Note that both the interictal spikes as well as the ictal discharge propagate to the left frontal regions (6/8-9). The four right sections of EEG-recording represents the "tertiary" seizure propagation to the contralateral hemisphere. 


\section{TOTAL OUTCOME}

(30) I(21) II (0) III (4) IV (5)

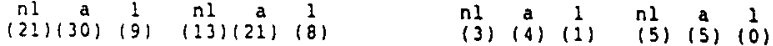
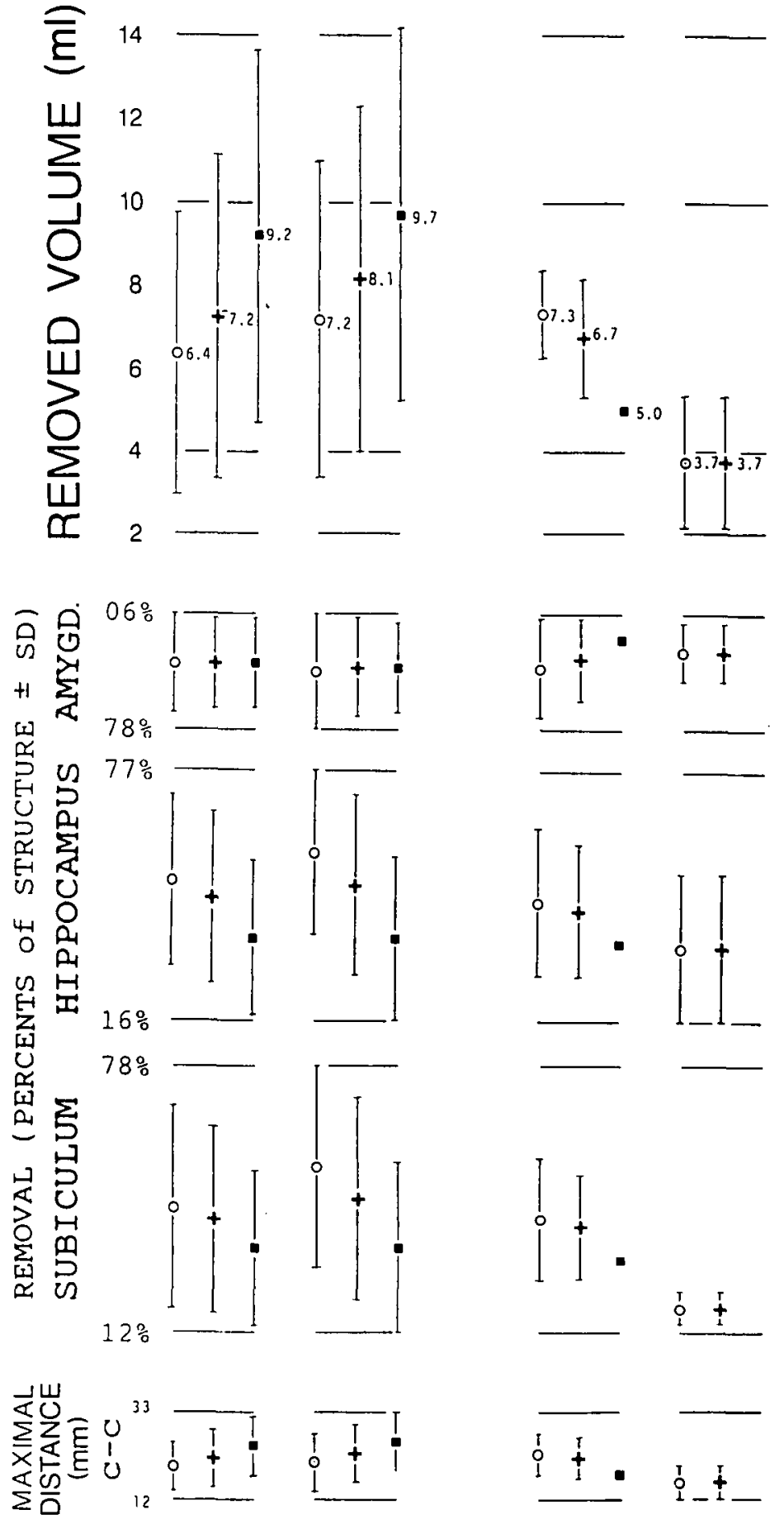

Figure 5 - Removed volume in ml (top), percentage of removal per indicated limbic subcompartment (middle), and maximal length of the resection in the cranio-caudal axis (bottom), in 30 patients who underwent selective amygdalohippocampectomy. Data are displayed for the total number of patients and according to the epileptological outcome (I-IV, for definition see text; further abbreviations: nl, non-lesional; a, all; I, lesional). Number in brackets refers to the underlying patients. The numerical values of the means are given with the figure. 
Table 1: Most recent and year-by-year epileptological outcome of patients treated with selective amygdalohippocampectomy. The bottom part of the table shows the outcome of 58 non-lesional patients preoperatively classified into "causal" and "palliative" operations (see text). $\bar{x}$, mean in months; SD, standard deviation in months.

\begin{tabular}{|c|c|c|c|c|c|c|c|c|c|}
\hline \multirow[b]{2}{*}{ Follow-up Groups } & \multirow[b]{2}{*}{ Total } & \multirow[b]{2}{*}{ I } & \multirow{2}{*}{\multicolumn{2}{|c|}{$\begin{array}{c}\text { II } \\
\text { (Number of Patients) }\end{array}$}} & \multicolumn{2}{|c|}{ Outcome Categories } & \multirow{2}{*}{\multicolumn{2}{|c|}{$\begin{array}{l}\text { II } \\
\text { (Percents) }\end{array}$}} & \multirow[b]{2}{*}{ IV } \\
\hline & & & & & IV & I & & & \\
\hline $\begin{array}{l}\text { Most Recent Follow-Up } \\
(\bar{x} 47 ; \text { SD 30.8) }\end{array}$ & 177 & 105 & 13 & 20 & 39 & 59 & 7 & 11 & 22 \\
\hline \multicolumn{10}{|l|}{ Year-by-Year Outcome } \\
\hline 1 year & 177 & 115 & 9 & 20 & 33 & 65 & 5 & 11 & 19 \\
\hline 2 years & 138 & 82 & 9 & 17 & 30 & 59 & 7 & 12 & 22 \\
\hline 3 years & 106 & 63 & 4 & 13 & 26 & 59 & 4 & 12 & 25 \\
\hline 4 years & 91 & 57 & 4 & 12 & 18 & 63 & 4 & 13 & 20 \\
\hline 5 years & 73 & 43 & 5 & 9 & 16 & 59 & 7 & 12 & 22 \\
\hline $6-8$ years & 34 & 20 & 1 & 4 & 9 & 59 & 3 & 12 & 26 \\
\hline $9-13$ years & 10 & 7 & 1 & 1 & 1 & 70 & 10 & 10 & 10 \\
\hline $\begin{array}{l}\text { Causal AHE } \\
(\bar{x} 50.4 ; \text { SD 35.3) }\end{array}$ & 30 & 22 & 6 & - & 2 & 73 & 20 & - & 7 \\
\hline $\begin{array}{l}\text { Palliative AHE } \\
(\bar{x} 55.7 ; \text { SD } 31.0)\end{array}$ & 28 & 3 & - & 9 & 16 & 12 & - & 31 & 57 \\
\hline
\end{tabular}

Table 2: Antiepileptic drug (AED) treatment at different postoperative follow-up periods.

\begin{tabular}{lrrrr}
\hline \hline & \multicolumn{4}{c}{ Follow-up Periods (Years) } \\
& $9-13$ & $6-8$ & 5 & 1 \\
\hline No AED & $7(70 \%)$ & $15(43 \%)$ & $31(42 \%)$ & $28(16 \%)$ \\
I AED & - & $4(11 \%)$ & $14(19 \%)$ & $82(46 \%)$ \\
2 AEDs & $1(10 \%)$ & $9(26 \%)$ & $17(23 \%)$ & $43(24 \%)$ \\
$\geq 3$ AEDs & $2(20 \%)$ & $6(17 \%)$ & $11(15 \%)$ & $24(14 \%)$ \\
Total & $10(100 \%)$ & $34(100 \%)$ & $73(100 \%)$ & $177(100 \%)$ \\
(Number of Patients) & & & \\
\hline
\end{tabular}

Table 3: Antiepileptic drug (AED) treatment versus postoperative seizure outcome classification (I - IV) 1 year after selective amygdalohippocampectomy.

\begin{tabular}{ccrcr}
\hline \hline \multicolumn{5}{c}{ AED Treatment } \\
Outcome & No AED & I year after selective AHE \\
Categories & 1 AED $(\%)$ & N AEDs & > 3 AEDs \\
\hline I & $28(100 \%)$ & $57(70 \%)$ & N $(\%)$ & N (\%) \\
II & - & $6(7 \%)$ & $2(51 \%)$ & $8(33 \%)$ \\
III & - & $8(10 \%)$ & $7(16 \%)$ & $1(4 \%)$ \\
IV & - & $11(13 \%)$ & $12(28 \%)$ & $10(42 \%)$ \\
Total (N 177) & $28(100 \%)$ & $82(100 \%)$ & $43(100 \%)$ & $24(100 \%)$ \\
\hline
\end{tabular}

come category remains fairly stable throughout the years. A preoperative classification into "causal" and "palliative" AHE was done in patients without tumors, vascular malformations and hamartomas. The bottom part of Table 1 shows that "causal" AHE yields to better epileptological outcome.

In order to describe the success rate of the selective AHE it is necessary to consider the pre-/postoperative modifications in the antiepileptic drug (AED) regimen. Whereas preoperatively all our patients had high doses of AEDs in polytherapy, postoperatively 49 out of 177 patients $(28 \%)$ had a complete discontinuation of AEDs. AEDs are not required by $70 \%$ of the patients in the longest follow up group (9-13 years, $N=10$ ), $43 \%$ of the patients with a postoperative follow up of 6-8 years $(\mathrm{N}=34)$, and $42 \%$ of patients with a follow up of 5 years $(\mathrm{N}=73$, see Table 2).

The mean postoperative period before discontinuation of the AEDs was 20.1 months (ranging from 6 to 60 , see also Table 3 ). Forty-six patients (94\%) remained seizure free following AED discontinuation. Two patients had recurrence of seizures: one patient had persistent seizures despite immediate de-novo AED treatment (AEDs discontinued 6 months postoperatively, follow up with de-novo AED treatment 6 months), the other patient became seizure free after readministration of AEDs (discontinued 6 months postoperatively, follow up with de-novo AED treatment for 60 months). One patient experienced rare auras after AED discontinuation and elected not to be treated with AEDs (AED discontinuation 42 months postoperatively; follow up period without AEDs 24 months).

Phenytoin was given in $56 \%$ of the 82 patients as monotherapy, phenobarbital or primidone in $22 \%$ and carbamazepine in $21 \%$. When two AEDs were given $(\mathrm{N}=43) 79 \%$ of the patients received phenytoin, $44 \%$ phenobarbital or primidone, $37 \%$ carbamazepine, $26 \%$ valproate, and $14 \%$ diazepame or other AEDs.

\section{Neuropsychological Outcome Following Amygdalohippocampectomy}

Several studies ${ }^{11,34-36}$ have been conducted with patients of our AHE series comparing pre- and postoperative neuropsychological performances, in particular learning and memory. Birri et al. ${ }^{34}$ and Gonser ${ }^{36}$ reported that postoperative neuropsychological performance was better in patients with selective AHE compared to patients with a classical anterior two-thirds TL resection. Furthermore, we showed that the postoperative neuropsycholog- 
ical performance is related to the epileptological outcome. ${ }^{11}$ Patients seizure-free after selective AHE did much better than those with persisting seizures. Moreover, it has been shown that the performance of the non-operated hemisphere improves more than the operated one. This phenomenon was explained by the cessation of the pathological interference from the contralateral side after the operation.

Although more detailed neuropsychological studies of the effects of AHE have to be done, the main findings of the study of Birri et al $^{34}$ remain still valid (see Figure 6 ). The updated results based on 70 patients showing the pre-/postoperative performance changes obtained with Nadig's leaming and memory test are shown in Figure 7. The learning performance was examined by the Nadig's test consisting of three series of 15 items each drawn or written in black ink on white cards $(15 \times 10 \mathrm{~cm})$. The items of the first series were nonsense designs ("designs"). The second consisted of drawings of common objects ("drawings") and the third of concrete nouns ("nouns"). The items were presented until the patient was able to reproduce at least 12 items, but for a maximum of 5 trials. The reproduction of as
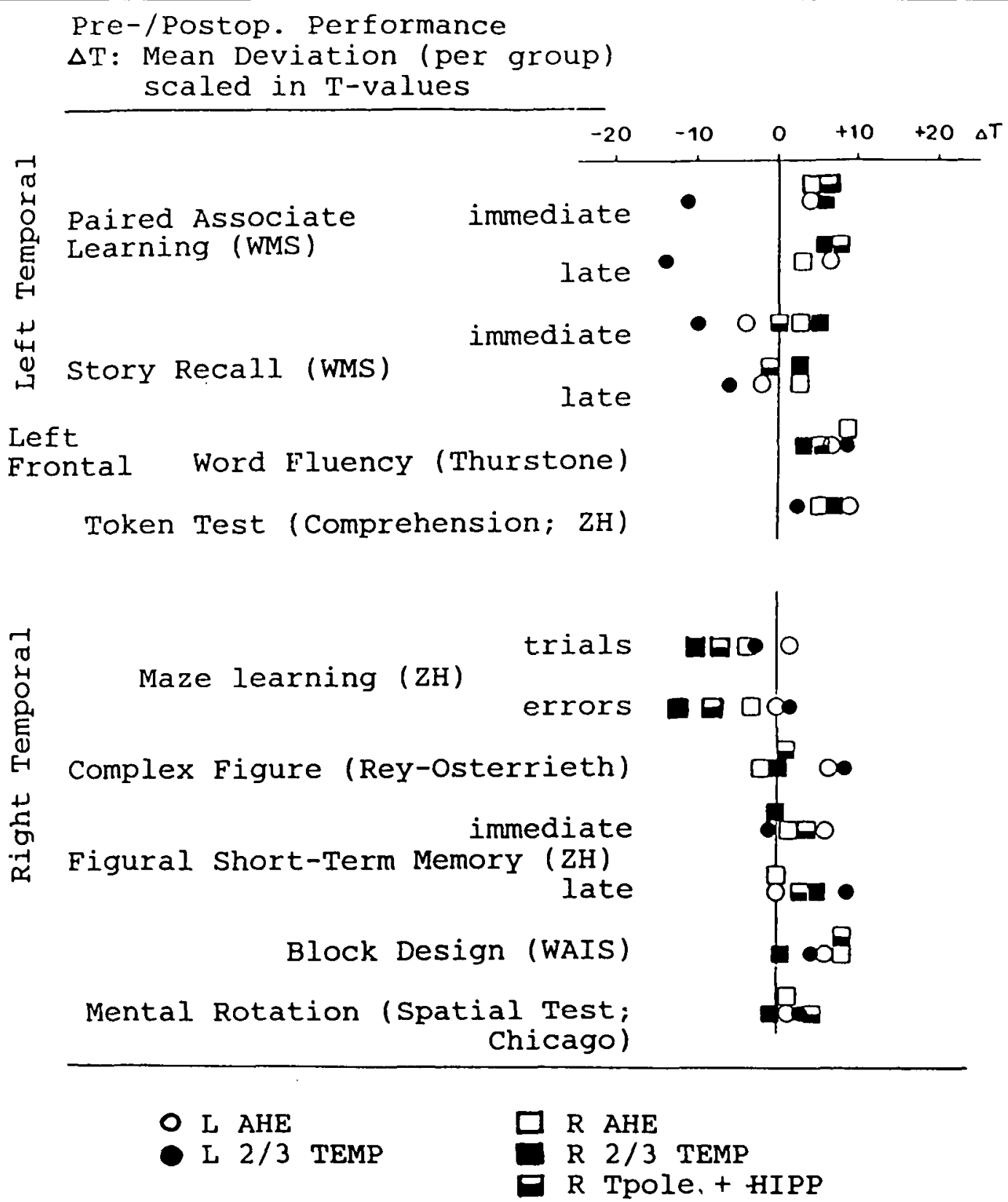

Figure 6-Comparison of pre-/postoperative performance in patients with different types of temporal lobe resections for treatment of medically refractory complex partial seizures: Selective amygdalohippocampectomy (AHE; left $N=3$, right $N=3$ ), removal of right temporal polar area, amygdala and hippocampal formation $(R$ Tpole $+H I P P ; N=3)$, and "classical" two-thirds temporal lobe resection $(2 / 3$ TEMP; left $N=2 ;$ right $N=3$ ). (Modified from Birri et al., 1982). 
many items as possible of each series (design, drawing, nouns) after a distraction interval of 30 minutes made up the memory performance. In order to avoid memory savings from pre- to postoperative testing, two similar but not identical parallel versions $(\mathrm{A} / \mathrm{B})$ of this test were used. Half of the patients were tested preoperatively with version $A$ and postoperatively with Version $B$ and vice versa.

We have recently examined the role of TL lesions in memorizing auditory nonverbal material (pure tones). Patients treated with selective AHE were included in this study. Controls and patients with mesiobasal TL or frontal lesions had to identify target tones in series consisted of target and distractor tones randomly presented. Patients with right TL lesions showed markedly reduced task performances when more than three different target tones had to be identified. The decrement in performance of these patients was attributed to poor structuring of the stimuli to reduce memory load and to lack of selection for adequate response. This study 37 confirms the results presented by the
Montreal group analyzing data from patients with varying extents of unilateral hippocampal excisions ${ }^{38}$. We support that the hippocampus plays a role in some, but not all, memory tasks depending on the kind of stimuli and complexity of the task. Even small differences in the experimental protocol may be sufficient to lower the performance on a task that normally is not under the influence of the hippocampal function.

\section{CONCLUSION}

Selective AHE offers a high probability of cure only in patients with a well-defined, precisely localized "epileptogenic area", i.e., seizure focus. Only a small portion of all patients with epilepsy can meet the criteria for selective surgical interventions. However, we conclude that if the criteria are met, selective AHE is preferable to the "standard" anterior temporal lobectomy and represents an approach towards a more selective but still effective surgical treatment.

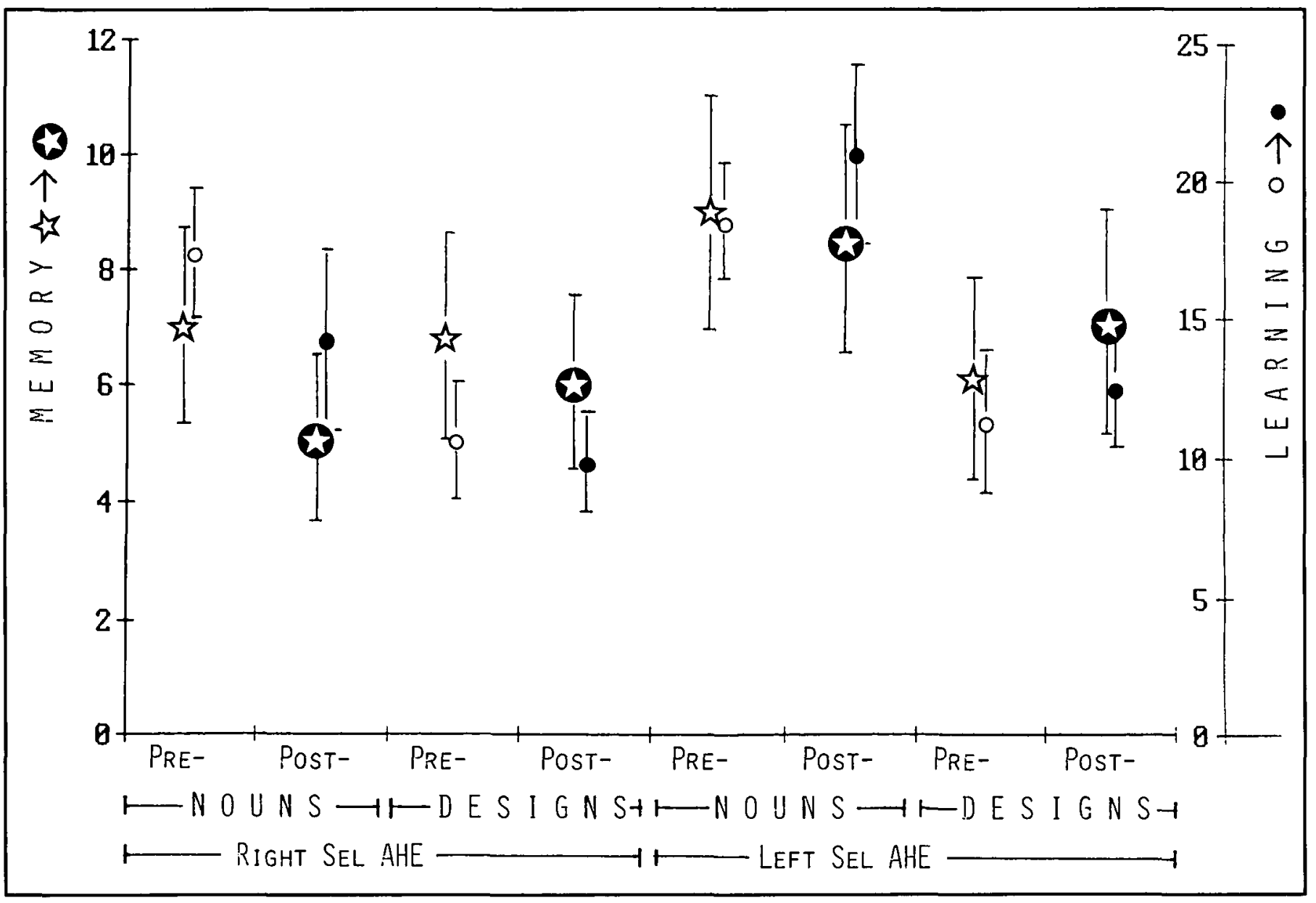

Figure 7 - Pre-and postoperative performance changes obtained with Nadig's learning and memory test battery in 35 patients with right and 35 patients with left selective amygdalohippocampectomy. Stars refer to memory, circles to learning. Empty symbols indicate preoperation results, full symbols are postoperative. Symbols represent means and standard deviation. The learning performance is based on the number of trials necessary to achieve the correct reproduction of $12 / 15$ items (see text). The performance values of the learning scale (0-25) have the following meanings: $4=2$ trials, $8=3$ trials, $12=4$ trials, $16=5$ trials.

If at the fifth trial the patient is still unable to reproduce $12 / 15$ items, the sum of the correctly reproduced items are taken into account. The memory scale $(0-12$, left) indicates the number of items that could not be reproduced after a distraction interval of 30 minutes, i.e. a memory performance of 5 indicates that 10 out of 15 items were correctly reproduced, whereas a score of 8 means that only 7 items were correctly reproduced. 


\section{ACKNOWLEDGEMENT}

I want to thank Dr. Isabelle Germano for editorial suggestions.

\section{REFERENCES}

1. Jasper HH. Localized analyses of the function of the human brain by the electroencephalogram. Arch Neurol \& Psychiat 1936; 36: 1131-1134.

2. Penfield W, Jasper H. Epilepsy and the Functional Anatomy of the Human Brain. Little, Brown, Boston; 1954.

3. Feindel W. Temporal lobe seizures. In: Magnus O, Lorentz de Haas AM, eds. The Epilepsies (Handbook of Clinical Neurology, Vol. 15). North-Holland Publ Company, Amsterdam, 1974; 87-106.

4. Rasmussen T. Surgical treatment of patients with complex partial seizures. In: Penry JK, Daly DD, eds. Advances in Neurology. Raven Press, New York, 1975; Vol. 11, 415-449.

5. Gloor P. Electroencephalography and the role of intracerebral depth electrode recordings in the selection of patients for surgical treatment of epilepsy. In: Porter RJ, Mattson R, Ward AA, Dam M, eds. Advances in Epileptology: $X V$ th Epilepsy International Symposium. Raven Press, New York; 1984: 433-437.

6. Milner B, Branch C, Rasmussen T. Study of Short-term memory after intracarotid injection of Sodium Amytal. Trans Am Neurol Assoc 1962; 87: 224-226.

7. Wieser HG. Electroclinical features of the psychomotor seizure. Gustav Fischer-Butterworths, Stuttgart-London; 1983.

8. Williamson PD, Wieser HG, Delgado-Escueta AV. Clinical characteristics of partial seizures. In: Engel J Jr, ed. Surgical Treatment of the Epilepsies. Raven Press, New York; 1987; 101-120.

9. Wieser HG, Moser S. Improved multipolar foramen ovale electrode monitoring. J Epilepsy 1988; 1: 13-22.

10. Quesney LF, Gloor P. Special extracranial electrodes. In: Wieser HG, Elger CE, eds. Presurgical Evaluation of Epileptics. Springer, Berlin, Heidelberg, New York; 1987: 162-176.

11. Wieser HG. Selective amygdalohippocampectomy: Indications, investigative technique and results. In: Symon $\mathrm{L}$ et al., eds. Advances and Technical Standards in Neurosurgery. Springer, Vienna, New York; 1986a; Vol. 13: 39-133.

12. Wieser HG. Psychomotor seizures of hippocampal-amygdalar origin. In: Pedley TA, Meldrum BS, eds. Recent Advances in Epilepsy 3. Churchill Livingstone, Edinburgh, London, Melbourne, New York; 1986b; 57-79.

13. Wieser HG. The phenomenology of limbic seizures. In: Wieser HG, Speckman EJ, Engel J Jr, eds. The Epileptic Focus. John Libbey \& Co, London, Paris; 1987a; 113-136.

14. Wieser HG, Yasargil MG. Selective amygdalohippocampectomy as a surgical treatment of mesiobasal limbic epilepsy. Surg Neurol 1982; 17: 445-457.

15. Yasargil MG, Teddy PJ, Roth P. Selective amygdalohippocampectomy: operative anatomy and surgical technique. $I n$ : Symon $\mathrm{L}$ et al., eds. Advances and Technical Standard in Neurosurgery, Vol 12. Springer, Vienna, New York; 1985; 93-123.

16. Wieser HG. Selective amygdalo-hippocampectomy for temporal lobe epilepsy. Epilepsia 29, Suppl 2, 1988b; 100-113.

17. Yasargil MG, Wieser HG. Selective amygdalophippocampectomy at the University Hospital, Zürich. In: Engel Jr J, ed. Surgical Treatment of the Epilepsies. Raven Press, New York; 1987a; 653-658.

18. Yasargil MG, Wieser HG. Selective microsurgical resections. In: Wieser HG, Elger CE, eds. Presurgical Evaluation of Epileptics. Springer, Berlin, Heidelberg, New York; 1987b; 352-360.

19. Siegel AM, Wieser HG, Wichman W, et al. Relationship between MR-imaged total amount of tissue removed, resection scores of specific mediobasal limbic subcompartments and clinical outcome following selective amygdalohippocampectomy. Epilepsy Res 1990; 6: 55-65.

20. Siegel AM, Wieser HG. A detailed follow-up study on the Zürich amygdalhippocampectomy series. J Epilepsy (submitted); 1991.

21. Wieser HG, Siegel AM. Analysis of foramen ovale electrode recorded seizures and correlation with outcome following amygdalohippocampectomy. Epilepsia (submitted); 1990.

22. Yasargil MG. Microneurosurgery, Vol. I. Thieme, Stuttgart; 1984.

23. Renella RR. Microsurgery of the Temporo Medial Region. Springer-Verlag, Wien, New York; 1989.

24. Wieser HG. Stereo-electroencephalography. I $n$ : Wieser HG, Elger $\mathrm{CE}$, eds. Presurgical Evaluation of Epileptics. Springer, Berlin, Heidelberg; 1987b; 192-204.

25. Wieser HG, Valavanis A, Roos A, Isler P, Renella RR. "Selective" and "superselective" temporal lobe Amytal tests: 1 . Neuroradiological, neuroanatomical, and electrical data. In: Manelis J, Bental E, Loeber JN, Dreifuss F, eds. Advances in Epileptology, Vol. 17. Raven Press, New York; 1989a; 20-27.

26. Wieser HG, Landis T, Regard M, Schiess R. "Selective" and "superselective" temporal lobe Amytal tests: 2. Neuropsychological test procedure and results. In: Manelis J, Bental E, Loeber JN, Dreifuss F eds. Advance in Epileptology, Vol. 17. Raven Press, New York; 1989b; 28-33.

27. Wada J. A new method for the determination of the side of cerebral speech dominance. A preliminary report on the intracarotid injection of Sodium Amytal in man. Igaku to Seibutssugaku (Medicine and Biology), 1949; 14: 221-222.

28. Wada J, Rasmussen T. Intracarotid injection of Sodium Amytal for the lateralization of cerebral speech dominance. Observations on 123 patients. J Neurosurg 1960; 17: 266-282.

29. Wieser HG. Selective Amytal memory tests: correlation with postoperative results. Epilepsia 1989; 30: (5), 724.

30. Babb TL, Brown WJ. Neuronal, dentritic, and vascular profiles of human temporal lobe epilepsy correlated with cellular physiology in vivo. In: Delgado-Escueta AV, Ward AA Jr, Woodbury DM, Porter RJ, eds. Basic Mechanisms of the Epilepsies. Advances in Neurology, Vol 44. Raven Press, New York; 1986; 949-966.

31. Wieser HG. Human limbic seizures: EEG studies, origin, and patterns of spread. In: Meldrum BS, Ferrendelli JA, Wieser HG, eds. Anatomy of Epileptogenesis. John Libbey \& Co, London, Paris; 1988a; 127-138.

32. Duvernoy HM. The Human Hippocampus. Bergman Verlag, Munich; 1988.

33. Engel J Jr. Outcome with respect to epileptic seizures. In: Engel J Jr, ed. Surgical Treatment of the Epilepsies. Raven Press, New York; 1987; 553-571.

34. Birri R, Perre E, Wieser HG. Der Einfluss verschiedener Temporallappenoperationen auf das Gedächtnis bei Epileptikern. Nervenarzt 1982; 53: 144-149.

35. Nadig T, Wieser HG, Perret E. Leaming and memory performance before and after unilateral selective amygdalohippocampeciomy. In: Will BE, Schmitt P, Dalrymple-Alford JC, eds. Brain Plasticity, Leaming and Memory. Plenum Publ Co, New York; 1985: 397-403.

36. Gosner A, Perret E, Wieser HG. Ist der Hippokampus für Lernund Gedächtnisprozess notwendig? Nervenarzt; 1986; 57: 269-275.

37. Wittlieb-Verpoort E, Wieser HG. Tone discrimination in patients with temporal lobe lesion (submitted to Neuropsychologia); 1991.

38. Jones-Gotman M. Comment: psychological evaluation. In: Engel J $\mathrm{J} r$, ed. Surgical Treatment of the Epilepsies. Raven Press, New York; 1987; 197-201. 